\title{
Early instrumental predictors of long term neurodevelopmental impairment in newborns with perinatal asphyxia treated with therapeutic hypothermia
}

\author{
ALICE MONZANI ${ }^{1}$, GIANLUCA COSI ${ }^{2}$, GIULIA GENONI ${ }^{1}$, MARIA LAVRANO ${ }^{1}$, CIN- \\ ZIA PERUZZI ${ }^{3}$, ROBERTA POMELLA ${ }^{3}$, FEDERICA FERRERO ${ }^{2}$ \\ ${ }^{1}$ Division of Pediatrics, Department of Health Sciences, Università del Piemonte Orientale, Novara, Italy \\ ${ }^{2}$ Division of Neonatal Intensive Care Unit, Azienda Ospedaliero-Universitaria "Maggiore della \\ Carità", Novara, Italy \\ ${ }^{3}$ Division of Child Neurology and Psychiatry, Azienda Ospedaliero-Universitaria "Maggiore della \\ Carità", Novara, Italy
}

Corresponding author

Alice Monzani

Division of Pediatrics

Department of Health Sciences, Università del Piemonte Orientale

V. Solaroli 17, 28100 Novara, Italy

Phone: (39).0321.660693

Fax: (39).0321.3733598

E-mail:alice.monzani@med.uniupo.it

\section{ABSTRACT}

Background. Hypoxic-ischemic encephalopathy (HIE) is a leading cause of disability in full-term newborns. Long-term consequences of HIE, even when treated by hypothermia, are not easily predictable. Aims. To assess the potential role of electroencephalography and neuroimaging parameters as early predictors of neurodevelopmental outcome in HIE newborns treated with hypothermia.

Methods. We retrospectively evaluated 13 HIE patients treated with hypothermia in January 2012-September 2014. We reviewed their amplitude-integrated electroencephalography (a-EEG) at 6,12 and 24 hours (h), cranial ultrasonography (US) at $12,72 \mathrm{~h}$ and $>7$ days of life (DOL) and brain magnetic resonance (MRI) performed at 7-28 DOL, according to validated scores. aEEG, US and MRI patterns were correlated to neurodevelopmental outcome at 1824 months, considered as negative if one of the following was present: Mental Development Index $(\mathrm{MDI})<85$, motor, visual or hearing impairment.

Results. The severity of a-EEG, US and MRI alterations at each time point was not different according to the outcome. MDI was negatively correlated with aEEG score at $12 \mathrm{~h}(\mathrm{R}=-0.571, \mathrm{p}=0.04)$ and with US score at $72 \mathrm{~h}(\mathrm{R}=-0.630, \mathrm{p}=0.02)$. A positive correlation was found between aEEG score at $6 \mathrm{~h}$ and US score at $>7 \mathrm{DOL}$
$(\mathrm{R}=0.690, \mathrm{p}=0.013)$. US alterations of the cortical matter at $72 \mathrm{~h}$ were directly correlated with a-EEG score at $12 \mathrm{~h}(\mathrm{R}=0.606$, $\mathrm{p}=0.028)$ and $24 \mathrm{~h}(\mathrm{R}=0.605, \mathrm{p}=0.029)$.

Conclusions. Early instrumental evaluations, in particular aEEG and US, seem to predict neurodevelopmental outcome at 18-24 months in HIE newborns treated with hypothermia.

Key words: asphyxia, hypoxic-ischemic encephalopathy, hypothermia, newborn

\section{INTRODUCTION}

Hypoxic-ischemic encephalopathy (HIE), following neonatal asphyxia, is a leading cause of neurological disability in newborns: (1) it can result in serious consequences such as death, cerebral palsy, epilepsy, cognitive, behavioural and developmental deficits. $(2,3)$ Brain damage is an evolutionary process characterized by an acute stage of neuronal necrosis followed by a phase of reperfusion injury characterized by neural apoptosis. Hypothermic treatment limits brain damage, reducing mortality and disability at 18-24 months of life. (4) However, long-term consequences of perinatal asphyxia are not easily predictable. (3)

Therefore, the aim of this study was to assess the potential role of amplitude-integrated electroencephalography (a-EEG) background patterns, cranial ultrasonogra- phy (US) and cerebral magnetic resonance imaging (MRI) findings as early predictors of neurodevelopmental outcome at $18-24$ months in neonates undergoing therapeutic hypothermia for HIE.

\section{MATERIALS AND METHODS}

We retrospectively analysed data of all the patients who underwent hypothermic treatment from 1 January 2012 to 30 September 2014 in the Neonatal Intensive Care Unit of Maggiore della Carità University Hospital, Novara, Italy. Hypothermic treatment was performed according to the current national guidelines for the management of HIE. $(5,6)$

For each subject, a-EEG, cranial US and cerebral MRI, performed at scheduled time-points, were reviewed according to validated scores. (7-9)

\section{a-EEG}

A trained nurse or technician applied surface electrodes at C3-C4 locations according to the international $10-20$ system. a-EEG was recorded for all the cooling period and for six hours after rewarming. a-EEG recordings were reviewed by a pediatric neurologist (C.P.) skilled in neonatal a-EEG and blinded to clinical factors. A severity score, based on the classification reported by Murray et al. (7) was assigned to tracings recorded at 6,12 and 24 hours 
of life, as follows:

- Grade 0 (normal a-EEG): continuous pattern with physiological characteristics

- Grade 1 (mildly abnormal): continuous pattern with slightly abnormal activity (slight asymmetry, mild depression voltage, poorly differentiated sleepwake cycle)

- Grade 2 (moderately abnormal): discontinuous activities with interburst $<10$ seconds, not differentiated sleepwake cycle, or clear asymmetry or asynchrony

- Grade 3 (severe abnormalities): discontinuous activities with interburst of 1060 seconds, severe depression voltage, or lack of sleep-wake cycle

- Grade 4 (inactive/flat EEG): basic activities $<10$ microvolts or severe discontinuity with interburst range $>60$ seconds.

\section{Cranial US}

Cranial US was performed for all patients at three time-points: $\mathrm{t}=0$ (within 24 hours), $\mathrm{t}=72$ (at 72 hours) and $\mathrm{t}>7$ DOL (at 7-10 days of life). All US images were blindly reviewed by a single neonatologist (G.C.) skilled in cerebral US. For each patient different anatomical sites were evaluated: basal ganglia, periventricular and subcortical white matter, cortical grey matter, and the severity of injuries was classified according to the severity score proposed by DeVries. (8)

The basal ganglia were classified as: normal in the absence of ultrasound abnormalities, slightly altered in the presence of focal hemorrhage or hyperechogenicity of the lateral thalamus, moderately altered in the case of hyperechogenicity of the thalamus and putamen, seriously altered if the caudate and the entire thalamus were involved. The white and cortical substance were classified as: normal in the absence of ultrasound abnormalities, slightly altered in the case of focal hemorrhage of the periventricular white matter or widespread hyperechogenicity predominant in the paraventricular and parasagittal areas, moderately altered in the absence of cortical profile in one or both cerebral hemispheres, severely impaired in the case of diffuse hyperechogenicity of the white matter with greater involvement of the subcortical substance.

\section{Brain MRI}

Brain MRI was performed between 7 and 28 days of life and different anatomical sites were evaluated: posterior limb of the internal capsule (PLIC), basal ganglia, periventricular white matter and subcortical and cortical grey matter. The severity of injuries was classified according to the severity score proposed by Cheong JL et al. (9) The PLIC was classified as normal/ abnormal, where the abnormality was defined by the reduction or absence of the intensity signal on T1/T2 sequences and/ or by a reduced or increased diffusion in DWI sequences. The basal ganglia were classified as normal/moderately abnormal in the absence or minimum focal alterations of signal in T1/T2 sequences and/or normal diffusion characteristics, and moderately/severely altered in the case of multiple or diffuse signal alterations in T1/T2 sequences and/or qualitative abnormalities of DWI sequences. The white matter was classified as normal/mildly abnormal in the absence or minimal alterations on $\mathrm{T} 1 /$ $\mathrm{T} 2$ sequences and/or in the case of normal diffusion characteristics in DWI sequences, and as moderately/severely abnormal in the case of signal alterations in T1/T2 or diffusion alterations in DWI sequences extending to the subcortical white matter or in more than three white matter areas.

The cortical gray matter was classified as normal/mildly abnormal in the absence of signal alterations in T1/T2 or diffusion abnormalities in 2 or less areas (including the central sulcus, the inter-hemispheric fissure and the insular region), and moderately/severely abnormal in the case of more extensive involvement.

\section{Neurodevelopmental evaluation}

For all patients, a development evaluation was performed between 18 and 24 months of life by a pediatric neurologist (R.P.). Children were tested by Mental Development Index (MDI) of the Bayley Scales of Infant Development and classified according to their score as subjects with accelerated performance ( $\mathrm{MDI} \geq 115)$, within the normal range (MDI 85-114), slightly delayed (MDI 70-84) and significantly delayed (MDI $\leq 69$ ). (10) Neurological examination was performed according to Amiel Tison assessment, (11) and the presence of motor, hearing or visual impairment at 18-24 months was recorded in order to set the grade of disability. Patients were divided into two groups according to their neurodevelopmental outcome at 1824 months, considered as negative if one of the following was present: Mental Development Index (MDI) score $<85$, motor, hearing or visual impairment.

\section{Statistical analysis}

Data are presented as numbers (percentages) or mean values $( \pm S D)$. Differences be- tween subjects with positive and negative neurodevelopmental outcome were evaluated by chi-square test (or Fischer test as appropriate) for categorical variables and by Mann-Whitney U test for continuous variables.

Correlation analyses were performed by Spearman's rank test.

A p value $<0.05$ was considered significant. Statistical analysis was performed using SPSS version 17.0 (Chicago, IL, USA).

\section{RESULTS}

The study population consisted of 13 patients $(\mathrm{M}: \mathrm{F}=6: 7)$. Out of 13 enrolled patients, $8(61.5 \%)$ had a positive neurodevelopmental outcome $(\mathrm{M}: \mathrm{F}=6: 2)$ and 5 (38.5\%) had a negative outcome ( $\mathrm{M}: \mathrm{F}=1$ : 4) at 18-24 months. Characteristics of enrolled patients for the four items included in the definition of neurodevelopmental outcome (MDI score, motor, hearing and visual impairment) are shown in table 1. Mean MDI score at $18-24$ months was $104.38 \pm 13.75$ in the group with a positive outcome and $88.5 \pm 20.4$ in the negativeoutcome group.

The a-EEG severity scores at 6,12 and 24 hours were not different in subjects with positive and negative neurodevelopmental outcomes. Globally, there was an improving trend from 6 to 24 hours, with an increase in slight alterations at the expense of severe ones (table 2).

In regard to the cranial US, the two groups of subjects with positive and negative neurodevelopmental outcomes did not differ in severity of alterations in any anatomical site and at any time (table 3 ).

In regard to the brain MRI, the two groups did not differ in severity of alterations in any anatomical site. Severe anomalies were recorded at all sites in one patient belonging to the group with a negative outcome (table 4).

\section{CORRELATION ANALYSIS}

MDI score was negatively correlated with the severity of a-EEG alterations at 12 hours $(\mathrm{R}=-0.571, \mathrm{p}=0.042, \mathrm{df}=11$ for twotailed test) and with the severity of cortical alterations evaluated by US at 72 hours ( $\mathrm{R}=$ $-0.630, \mathrm{p}=0.021, \mathrm{df}=11$ for two-tailed test). The severity of US anomalies of the white matter at 7 DOL showed a direct correlation with the alterations of a-EEG recorded at 6 hours $(\mathrm{R}=0.690, \mathrm{p}=0.013, \mathrm{df}=11$ for two-tailed test).

The severity of US alterations of the corti- 
cal matter at $\mathrm{t}=72 \mathrm{~h}$ was directly correlated with the severity of a-EEG alterations at 12 hours ( $\mathrm{R}=0.606, \mathrm{p}=0.028, \mathrm{df}=11$ for two-tailed test) and at 24 hours $(\mathrm{R}=0.605$, $\mathrm{p}=0.029, \mathrm{df}=11$ for two-tailed test).

\section{DISCUSSION}

This study aimed to analyse the presence of early anomalies detected by a-EEG, cranial US and brain MRI, in neonates undergoing therapeutic hypothermia for HIE, and to assess their potential prognostic value with respect to neurodevelopmental outcomes at $18-24$ months.

Out of 13 newborns treated with therapeutic hypothermia for HIE, five had a negative outcome at 18-24 months on the basis of a pathological MDI and/or the presence of motor, hearing and/or visual impairment.

The first instrumental parameter taken into account was a-EEG recorded at 6, 12 and 24 hours of birth. No difference was found in the a-EEG severity scores at each time point between subjects with positive and negative neurodevelopmental outcomes. However, it could be supposed that it may be due to the small sample size, as at all times the prevalence of subjects with severe/flat a-EEG tended to be higher in subjects with a negative outcome. An improving trend from 6 to 24 hours was also globally found, with an increase of the slight alterations at the expense of the severe ones, that, however, tended to persist into the negative outcome group. Moreover, the severity of a-EEG alterations at 12 hours was indirectly correlated to MDI at 18-24 months, suggesting the potential prognostic value of a-EEG performed at 12 hours of life. Our findings are consistent with the results reported by Murray et al., (7) highlighting the improvement of EEG alterations from 6 to 48 hours and suggesting the importance of performing early EEG assessments as predictors of outcome after perinatal asphyxia, since normal or mildly abnormal EEG results within 6 hours of life were associated with normal neurodevelopmental outcomes at 24 months. Also, in the systematic review by van Laerhoven et al., (3) a-EEG was the most promising test with a sensitivity of $93 \%$ and a specificity of $90 \%$ in predicting long term neurodevelopmental outcomes. Regarding imaging methods, no significant difference was found in the severity score of US and MRI alterations at any time and in any site according to neurodevelopmental outcome. However, it should be pointed out that only one sub-

Table 1. Global assessment at 18-24 months of all subjects according to neurodevelopmental outcome.

\begin{tabular}{llll}
\hline & $\begin{array}{l}\text { All } \\
(\mathbf{n = 1 3})\end{array}$ & $\begin{array}{l}\text { Positive outcome } \\
(\mathbf{n = 8})\end{array}$ & $\begin{array}{l}\text { Negative outcome } \\
(\mathbf{n = 5})\end{array}$ \\
\hline MDI score & & & \\
\hline Non pathological & $9(69.2 \%)$ & $7(87.5 \%)$ & $2(40 \%)$ \\
Slightly low & $2(15.4 \%)$ & $1(12.5 \%)$ & $1(20 \%)$ \\
Significantly low & $2(15.4 \%)$ & 0 & $2(40 \%)$ \\
\hline Motor impairment & & & $2(40 \%)$ \\
\hline Yes & $2(15.4 \%)$ & 0 & $3(60 \%)$ \\
No & $11(84.6 \%)$ & $8(100 \%)$ & $1(20 \%)$ \\
\hline Hearing impairment & & & $3(60 \%)$ \\
\hline Yes & $1(7.7 \%)$ & 0 & $1(20 \%)$ \\
No & $9(69.2 \%)$ & $6(75 \%)$ & \\
Unknown & $3(23.1 \%)$ & $2(25 \%)$ & $2(40 \%)$ \\
Visual impairment & & & $3(60 \%)$ \\
\hline Yes & $2(15.4 \%)$ & 0 & \\
No & $11(84.6 \%)$ & $8(100 \%)$ & \\
\hline
\end{tabular}

MDI, Mental Development Index.

Table 2. Distribution of a-EEG patterns at 6, 12 and 24 hours in all subjects divided according to positive or negative neurodevelopmental outcome.

\begin{tabular}{|c|c|c|c|c|}
\hline & $\begin{array}{l}\text { All } \\
(n=13)\end{array}$ & $\begin{array}{l}\text { Positive outcome } \\
(n=8)\end{array}$ & $\begin{array}{l}\text { Negative outcome } \\
(n=5)\end{array}$ & $P$ value \\
\hline \multicolumn{5}{|l|}{ a-EEG at 6 hours } \\
\hline 0 (normal) & 0 & 0 & 0 & 0.229 \\
\hline 1 (mildly impaired) & $1(7.7 \%)$ & $1(12.5 \%)$ & 0 & \\
\hline 2 (moderately impaired) & $7(53.8 \%)$ & $5(62.5 \%)$ & $2(40 \%)$ & \\
\hline 3-4 (severe/flat) & $5(38.5 \%)$ & $2(25 \%)$ & $3(60 \%)$ & \\
\hline \multicolumn{5}{|l|}{ a-EEG at 12 hours } \\
\hline 0 (normal) & 0 & 0 & 0 & 0.124 \\
\hline 1 (mildly impaired) & $4(30.8 \%)$ & $4(50 \%)$ & 0 & \\
\hline 2 (moderately impaired) & $5(38.5 \%)$ & $2(25 \%)$ & $3(60 \%)$ & \\
\hline 3-4 (severe/flat) & $4(30.8 \%)$ & $2(25 \%)$ & $2(40 \%)$ & \\
\hline \multicolumn{5}{|l|}{ a-EEG at 24 hours } \\
\hline 0 (normal) & $1(7.7 \%)$ & $1(12.5 \%)$ & 0 & 0.697 \\
\hline 1 (mildly impaired) & $6(46.2 \%)$ & $3(37.5 \%)$ & $3(60 \%)$ & \\
\hline 2 (moderately impaired) & $3(23.1 \%)$ & $3(37.5 \%)$ & 0 & \\
\hline 3-4 (severe/flat) & $3(23.1 \%)$ & $1(12.5 \%)$ & $2(40 \%)$ & \\
\hline
\end{tabular}

Comparisons between subjects with positive and negative neurodevelopmental outcomes were performed by Fischer test.

ject showed severe alterations at all anatomical sites both on US and MRI, and he developed severe neurological sequelae (cerebral palsy with spastic-dystonic quadriplegia, serious impaired motor functions, slurred speech and feeding difficulties). The severe alterations were not present on US imaging performed at 24 hours of life, and appeared starting from 72 hours, persisting at the following time-points. From a long-term perspective, correlation analysis showed that MDI at 18-24 months was inversely correlated with the severity of US alterations of cortical matter at 72 hours, that was directly related with the severity of a-EEG alterations at 12 and 24 hours. Moreover, later alterations of the white matter, observed by cranial US at 7 DOL, showed a direct correlation with a-EEG alterations at 6 hours. Our data showed a tight interplay between a-EEG and cranial US in detecting anomalies following HIE. 
Previous data reported that cranial US has poor predictive accuracy, being highly examiner dependent, with a high false-positive rate. $(7,12)$ However, due to its safety and availability at the bedside, it can be suggested that, in the presence of alterations on cranial US performed starting at 72 hours, neuroradiological imaging and clinical follow-up is highly recommended in newborns with HIE. Conversely, normal cranial US findings can be reassuring of a positive neurodevelopmental outcome.

In our series, no correlation was found between MRI alterations and outcome indicators, probably due to the fact that only one subject displayed severe alterations on MRI. Our data are in contrast with those reported by van Laerhoven et al. (3) in their review, showing that brain MRI performed within two weeks of birth had the best sensitivity in predicting long term outcome.

The main limitation of our study was the small sample size, but all newborns who underwent hypothermic treatment in the considered period were included in the analysis.

In conclusion, our data confirm that aEEG is the earliest method capable of identifying alterations with a prognostic neurodevelopmental value in newborns undergoing therapeutic hypothermia for HIE. Moreover, cranial US performed starting from 72 hours, even with the limitation of low accuracy, should be considered a useful imaging technique for identifying which subjects will be deserving of neurological follow-up.
Table 3. Distribution of US patterns at 0, 72 hours and $>7$ days of life in all subjects, divided according to positive or negative neurodevelopmental outcomes.

\begin{tabular}{lllll}
\hline & $\begin{array}{l}\text { All } \\
(\mathbf{n = 1 3})\end{array}$ & $\begin{array}{l}\text { Positive outcome Negative outcome } \\
(\mathbf{n = 8})\end{array}$ & P value \\
\hline US at T=0 & & & & \\
\hline Basal ganglia & & & $5(100 \%)$ & 0.429 \\
\hline Normal & $12(92.3 \%)$ & $7(87.5 \%)$ & 0 & \\
Slightly impaired & $1(7.7 \%)$ & $1(12.5 \%)$ & 0 & 0.151 \\
Moderately impaired & 0 & 0 & 0 & \\
Seriously impaired & 0 & 0 & & \\
White matter & & & $3(20 \%)$ & \\
\hline Normal & $1(7.7 \%)$ & 0 & $1(20 \%)$ & \\
Slightly impaired & $11(84.6 \%)$ & $8(100 \%)$ & 0 & \\
Moderately impaired & $1(7.7 \%)$ & 0 & & \\
Seriously impaired & 0 & 0 & $4(80 \%)$ & \\
Cortical matter & & & $1(20 \%)$ & \\
\hline Normal & $11(84.6 \%)$ & $7(87.5 \%)$ & 0 & \\
Slightly impaired & $2(15.4 \%)$ & $1(12.5 \%)$ & 0 & \\
Moderately impaired & 0 & 0 & 0 &
\end{tabular}

\begin{tabular}{|c|c|c|c|c|}
\hline \multicolumn{5}{|l|}{ US at $\mathrm{T}=72 \mathrm{~h}$} \\
\hline \multicolumn{5}{|l|}{ Basal ganglia } \\
\hline Normal & $12(92.3 \%)$ & $7(87.5 \%)$ & $4(80 \%)$ & 0.206 \\
\hline Slightly impaired & $1(7.7 \%)$ & $1(12.5 \%)$ & 0 & \\
\hline Moderately impaired & 0 & 0 & 0 & \\
\hline Seriously impaired & 0 & 0 & $1(20 \%)$ & \\
\hline \multicolumn{5}{|l|}{ White matter } \\
\hline Normal & $1(7.7 \%)$ & 0 & $3(60 \%)$ & 0.745 \\
\hline Slightly impaired & $11(84.6 \%)$ & $8(100 \%)$ & $1(20 \%)$ & \\
\hline Moderately impaired & $1(7.7 \%)$ & 0 & 0 & \\
\hline Seriously impaired & 0 & 0 & $1(20 \%)$ & \\
\hline \multicolumn{5}{|l|}{ Cortical matter } \\
\hline Normal & $11(84.6 \%)$ & $7(87.5 \%)$ & $3(60 \%)$ & 0.063 \\
\hline Slightly impaired & $2(15.4 \%)$ & $1(12.5 \%)$ & $1(20 \%)$ & \\
\hline Moderately impaired & 0 & 0 & 0 & \\
\hline Seriously impaired & 0 & 0 & $1(20 \%)$ & \\
\hline \multicolumn{5}{|l|}{ US at $\mathrm{T}>7 \mathrm{DOL}$} \\
\hline \multicolumn{5}{|l|}{ Basal ganglia } \\
\hline Normal & $11(84.6 \%)$ & $7(87.5 \%)$ & $4(80 \%)$ & 0.708 \\
\hline Slightly impaired & $1(7.7 \%)$ & $1(12.5 \%)$ & 0 & \\
\hline Moderately impaired & 0 & 0 & 0 & \\
\hline Seriously impaired & $1(7.7 \%)$ & 0 & $1(20 \%)$ & \\
\hline \multicolumn{5}{|l|}{ White matter } \\
\hline Normal & $9(69.2 \%)$ & $6(75 \%)$ & $3(60 \%)$ & 0.558 \\
\hline Slightly impaired & $3(23.1 \%)$ & $2(25 \%)$ & $1(20 \%)$ & \\
\hline Moderately impaired & 0 & 0 & 0 & \\
\hline Seriously impaired & $1(7.7 \%)$ & 0 & $1(20 \%)$ & \\
\hline \multicolumn{5}{|l|}{ Cortical matter } \\
\hline Normal & $12(92.3 \%)$ & $8(100 \%)$ & $4(80 \%)$ & 0.237 \\
\hline Slightly impaired & 0 & 0 & 0 & \\
\hline Moderately impaired & 0 & 0 & 0 & \\
\hline Seriously impaired & $1(7.7 \%)$ & 0 & $1(20 \%)$ & \\
\hline
\end{tabular}

DOL, days of life; US, ultrasound.

Comparisons between subjects with positive and negative neurodevelopmental outcomes were performed by Fischer test. 
Table 4. Distribution of MRI patterns in all subjects, divided according to positive or negative neurodevelopmental outcomes.

\begin{tabular}{|c|c|c|c|c|}
\hline & $\begin{array}{l}\text { All } \\
(n=13)\end{array}$ & $\begin{array}{l}\text { Positive outcome } \\
(n=8)\end{array}$ & $\begin{array}{l}\text { Negative outcome } \\
(n=5)\end{array}$ & P value \\
\hline \multicolumn{5}{|l|}{ PLIC at MRI } \\
\hline Normal & $9(69.2 \%)$ & $6(75 \%)$ & $3(60 \%)$ & \multirow[t]{4}{*}{0.471} \\
\hline Slightly impaired & $3(23.1 \%)$ & $2(25 \%)$ & $1(20 \%)$ & \\
\hline Moderately impaired & 0 & 0 & 0 & \\
\hline Seriously impaired & $1(7.7 \%)$ & 0 & $1(20 \%)$ & \\
\hline \multicolumn{5}{|l|}{ Basal ganglia at MRI } \\
\hline Normal & $8(61.5 \%)$ & $5(62.5 \%)$ & $3(60 \%)$ & \multirow[t]{4}{*}{0.734} \\
\hline Slightly impaired & $4(30.8 \%)$ & $3(37.5 \%)$ & $1(20 \%)$ & \\
\hline Moderately impaired & 0 & 0 & 0 & \\
\hline Seriously impaired & $1(7.7 \%)$ & 0 & $1(20 \%)$ & \\
\hline \multicolumn{5}{|l|}{ White matter at MRI } \\
\hline Normal & $6(46.15 \%)$ & $3(37.5 \%)$ & $3(60 \%)$ & \multirow[t]{4}{*}{0.745} \\
\hline Slightly impaired & $6(46.15 \%)$ & $5(62.5 \%)$ & $1(20 \%)$ & \\
\hline Moderately impaired & 0 & 0 & 0 & \\
\hline Seriously impaired & $1(7.7 \%)$ & 0 & $1(20 \%)$ & \\
\hline \multicolumn{5}{|l|}{ Cortical matter at MRI } \\
\hline Normal & $6(46.15 \%)$ & $3(37.5 \%)$ & $3(60 \%)$ & \multirow[t]{4}{*}{0.745} \\
\hline Slightly impaired & $6(46.15 \%)$ & $5(62.5 \%)$ & $1(20 \%)$ & \\
\hline Moderately impaired & 0 & 0 & 0 & \\
\hline Seriously impaired & $1(7.7 \%)$ & 0 & $1(20 \%)$ & \\
\hline
\end{tabular}

MRI, magnetic resonance imaging; PLIC, posterior limb of the internal capsule.

Comparisons between subjects with positive and negative neurodevelopmental outcomes were performed by Fischer test.

\section{REFERENCES}

1. Douglas-Escobar M, Weiss MD. Hypoxic-ischemic encephalopathy: a review for the clinician. JAMA Pediatr 2015;169:397-403.

2. Kurinczuk JJ, White-Koning M, Badawi N. Epidemiology of neonatal encephalopathy and hypoxic-ischaemic encephalopathy. Early Hum Dev 2010;86:329-38.

3. van Laerhoven H, de Haan TR, Offringa M, Post B, van der Lee JH. Prognostic tests in term neonates with hypoxic-ischemic encephalopathy: a systematic review. Pediatrics 2013;131:88-98.

4. Edwards AD, Brocklehurst P, Gunn AJ, Halliday H, Juszczak E, Levene M, et al. Neurological outcomes at 18 months of age after moderate hypothermia for perinatal hypoxic ischaemic encephalopathy: synthesis and meta-analysis of trial data. BMJ 2010;340:c363.

5. Ancora G, Pomero G, Ferrari F. Raccomandazioni per l'assistenza al neonato con encefalopatia ipossico-ischemica possibile candidato al trattamento ipotermico. Milano: Biomedia; 2009.

6. Mosalli R. Whole body cooling for infants with hypoxic-ischemic encephalopathy. J Clin Neonatol 2012;1:101-6.

7. Murray DM, Boylan GB, Ryan CA, Connolly S. Early EEG findings in hypoxic-ischemic encephalopathy predict outcomes at 2 years. Pediatrics 2009;124:e459-67.

8. Govaert P, De Vries LS. An Atlas of Neonatal Brain Sonography. 2nd ed. London, Cambridge: Mac Keith Press; 2010.

9. Cheong JL, Coleman L, Hunt RW, Lee KJ, Doyle LW, Inder TE, Jacobs SE. Infant Cooling Evaluation Collaboration. Prognostic utility of magnetic resonance imaging in neonatal hypoxic-ischemic encephalopathy: substudy of a randomized trial. Arch Pediatr Adolesc Med 2012;166:634-40.

10. Bayley NM. Bayley Scales of Infant Development. 2nd ed. San Antonio, TX: The Psychological Corporation; 1993.

11. Amiel-Tison C, Gosselin J. Neurological Development from Birth to Six Years. Baltimore: John Hopkins UniversityPress; 2001.

12. Reynolds PR, Dale RC, Cowan FM. Neonatal cranial ultrasound interpretation: a clinical audit. Arch Dis Child Fetal Neonatal Ed 2001;84:F92-5. 